\title{
Nd: YAG capsulotomy for posterior capsule opacification after combined clear corneal phacoemulsification and vitrectomy
}

\author{
Ilias Georgalas' \\ Petros Petrou ${ }^{2}$ \\ George Kalantzis² \\ Dimitrios Papaconstantinou ${ }^{2}$ \\ Chrysanthi Koutsandrea ${ }^{2}$ \\ loannis Ladas ${ }^{2}$ \\ 'Department of Ophthalmology, \\ "G. Gennimatas" Hospital of Athens, \\ NHS, Athens, Greece; ${ }^{2}$ Department \\ of Ophthalmology, University \\ of Athens, Athens, Greece
}

\begin{abstract}
Purpose: To evaluate the efficacy and safety of Neodymium:YAG (Nd:YAG) laser capsulotomy for posterior capsule opacification (PCO) following combined phacoemulsification and vitrectomy for the treatment of cataract in association with macular hole $(\mathrm{MH})$ or epiretinal membrane (ERM).

Methods: Retrospective clinical study of 34 eyes of 34 patients who underwent combined cataract surgery and vitrectomy, developed PCO, and subsequently underwent Nd:YAG laser capsulotomy. Follow-up examinations included visual acuity measurement, evaluation of intraocular lens (IOL) centration, intraocular pressure (IOP) measurement, and dilated fundus examination.
\end{abstract}

Results: Nd:YAG laser capsulotomy was performed in all 34 eyes. The mean age of the patients was 65.08 years (range 45-87) and the mean follow up period was 11.05 months (range 4-23). The mean time elapsed between the last intraocular operation and the development of PCO was 10.00 months for patients with previous ERM and 15.33 for those with $\mathrm{MH}(\mathrm{P}=0.001$, t-test for equality of means). None of our patients developed recurrence of $\mathrm{MH}$, retinal detachment, IOL dislocation, or permanent IOP elevation.

Conclusion: In our study, the most remarkable observation is that no complication occurred after the YAG capsulotomy, possibly because the eyes were vitrectomized and vitreous seems to play an important role in the occurrence of post-Nd:YAG complications. In addition we noted that PCO seems to occur earlier in the eyes undergoing combined surgery for cataract and ERM when compared with those where combined phacoemulsification and vitrectomy are performed for cataract and $\mathrm{MH}$.

Keywords: Nd:YAG capsulotomy, phacoemulsification, vitrectomy

\section{Introduction}

Cataract, epiretinal membranes (ERM), and macular holes $(\mathrm{MH})$ are distinct clinical entities frequently coexisting in the same patient.

Robert Machemer, who was the first to establish an experimental model of retinal detachment, is best known for his development of pars plana vitrectomy for the treatment of vitreous hemorrhages in proliferative diabetic retinopathy. ${ }^{1}$ Nowadays, almost four decades since Machemer's revolutionary work, performance of combined vitrectomy and phacoemulsification is common when both cataract and vitreoretinal disease are present. This approach is necessary to enable adequate visualization of the posterior pole during vitreoretinal procedures and even if the opaque lens does not reduce visual function prior to surgery, it often progresses postoperatively as a result of vitreoretinal operation and the use of intraocular gas or silicone oil. Additionally, combined surgery has been considered to reduce intraoperative complication rates and allows immediate visual rehabilitation with only one operation. ${ }^{2-4}$ 
Posterior capsular opacification (PCO) is the most common complication of cataract extraction, occurring in up to $33 \%$ of patients after five years. ${ }^{5,6} \mathrm{PCO}$, apart from visual impairment, can obscure fundus view and potentially compromise follow-up ability of patients with posterior segment pathology such as diabetic retinopathy and macular edema. Neodymium: YAG (Nd:YAG) laser capsulotomy, the treatment of choice, is not without complications, some of which might be sightthreatening such as macular edema and retinal detachment. ${ }^{7}$

Prognosis and complication rate of Nd:YAG laser capsulotomy in patients having undergone combined vitreoretinal surgery and phacoemulsification has been inadequately described in the literature. ${ }^{8-10}$ We reviewed a series of 34 eyes that developed $\mathrm{PCO}$ and required Nd:YAG laser capsulotomy after combined cataract and vitreoretinal surgery.

\section{Patients and methods}

We retrospectively reviewed the medical records of 34 patients (34 eyes) with PCO who had previously undergone combined pars plana vitrectomy with phacoemulsification and intraocular lens (IOL) implantation. All patients had surgery at the Department of Ophthalmology, Athens General Hospital 'G. Genimatas' by a single surgeon.

All patients presented with decreased visual acuity which was attributed to PCO during their follow up in our clinic. Nd:YAG laser capsulotomy was performed if it was clinically indicated by a decrease in visual acuity of two lines at least since previous examination or in the presence of a clinically opaque capsule. Nd:YAG laser capsulotomy was eventually performed in all 34 eyes. The procedure was performed under topical anesthesia (tetracaine drops), and pupil dilatation was achieved with the use of tropicamide $1 \%$ and phenylephrine $10 \%$. The procedure was interrupted if more than five IOL pits were observed. Postoperative use of dexamethasone $0.1 \%$ and iopidine drops were prescribed for one week. Follow up examinations included visual acuity measurement, evaluation of IOL centration, intraocular pressure (IOP) measurement using Goldman applanation tonometry, and dilated fundus examination. The mean follow-up period (after Nd:YAG capsulotomy was performed) was 11 months.

\section{Results}

The demographic and clinical features of the patients are listed in Table 1. The mean age of the patients was 65.08 years (range 45-87) and the mean follow up period was 11.05 months (range 4-23).
All eyes had clinically significant lens opacification at the time of vitreoretinal surgery. The indications for vitreoretinal surgery included: vitreomacular traction syndrome (VMT) (four eyes), MH (12 eyes) and the presence of an ERM (18 eyes).

In all eyes after uncomplicated phacoemulsification, the IOL (foldable three-piece hydrophobic acrylic PC IOL Acrysof MA60BM; Alcon Laboratories, Fort Worth, TX) with $5.5 \mathrm{~mm}$ optic diameter was implanted in the capsular bag through a 4.5 to $5 \mathrm{~mm}$ capsulorhexis. Subsequently in eyes with MH (12 eyes) and with VMT (4 eyes) a 20-gauge-vitrectomy was performed with induction of PVD using the vitreous cutter to engage and pull on the peripapillary vitreous. A volume of $0.3 \mathrm{ml}$ of Trypan blue was injected in the vitreous cavity over the posterior pole and removed two minutes later; Internal limiting membrane (ILM) was peeled off from the macular area. Perfluoropropane $\mathrm{C}_{3} \mathrm{~F}_{8}$ gas $14 \%$ was used in the cases with MHs and the patient was instructed to adopt prone positioning for seven days. In eyes with ERMs, a 20-gauge-vitrectomy was performed, ERM peeling and subsequently the ILM was peeled of the macula with the aid of Trypan blue. No tamponade was used in any case with ERM or VMT.

Posterior capsule opacification was observed in all 34 eyes and required an Nd:YAG capsulotomy because of deterioration in postoperative best-corrected visual acuity. None of the eyes had persistent endotamponade when they underwent Nd:YAG capsulotomy.

Postcapsulotomy, four eyes developed moderate anterior chamber reaction that resolved with topical corticosteroids. In seven eyes IOP increased temporarily for a few days post-op, but it was well controlled with topical antiglaucoma agents. None of our patients developed retinal detachment or recurrence of $\mathrm{MH}$. IOL decentration or dislocation did not occur in any of the studied eyes. Cystoid macular edema was observed in two eyes that had undergone combined vitrectomy and phacoemulsification for ERM removal, however, the edema was also evident before the YAG-capsulotomy and did not augment after the procedure.

The visual acuity pre- and post-YAG capsulotomy, as well as the time elapsed until the appearance of PCO are listed in Table 1 and vary according to the nature of the disease. It seems that PCO appears earlier (Table 2; P $=0.001$, t-test for equality of means) in the eyes suffering an ERM (mean 10.00 months) compared to patients with $\mathrm{MH}$ disease (mean 15.33 months). No difference between the two groups was observed in age ( $\mathrm{P}=0.491$, $\mathrm{t}$-test for equality of means) or 
Table I Data for patients treated with Nd:YAG capsulotomy

\begin{tabular}{|c|c|c|c|c|c|c|}
\hline Case & Age (yr) & Sex & Condition & Follow-up (M) & VA pre-YAG & VA post-YAG \\
\hline I & 56 & Male & ERM & 6 & $20 / 63$ & $20 / 40$ \\
\hline 2 & 77 & Male & ERM & 8 & $20 / 80$ & $20 / 40$ \\
\hline 3 & 78 & Female & ERM & 17 & $20 / 50$ & $20 / 25$ \\
\hline 4 & 67 & Female & ERM & 18 & $20 / 50$ & $20 / 40$ \\
\hline 5 & 64 & Female & ERM & 13 & $20 / 40$ & $20 / 25$ \\
\hline 6 & 65 & Female & ERM & 12 & $20 / 80$ & $20 / 40$ \\
\hline 7 & 53 & Male & ERM & 7 & $20 / 63$ & $20 / 40$ \\
\hline 8 & 62 & Female & $\mathrm{MH}$ & 7 & $20 / 100$ & $20 / 63$ \\
\hline 9 & 54 & Male & $\mathrm{MH}$ & 4 & $20 / 40$ & $20 / 40$ \\
\hline 10 & 58 & Male & ERM & 5 & $20 / 50$ & $20 / 25$ \\
\hline II & 78 & Male & $\mathrm{MH}$ & 19 & $20 / 100$ & $20 / 63$ \\
\hline 12 & 83 & Male & VTS & 15 & $20 / 60$ & $20 / 40$ \\
\hline 13 & 45 & Male & ERM & 8 & $20 / 40$ & $20 / 25$ \\
\hline 14 & 56 & Male & $\mathrm{MH}$ & 5 & $20 / 40$ & $20 / 40$ \\
\hline 15 & 67 & Male & VTS & 7 & $20 / 100$ & $20 / 40$ \\
\hline 16 & 65 & Male & ERM & 10 & $20 / 50$ & $20 / 40$ \\
\hline 17 & 54 & Male & $\mathrm{MH}$ & 14 & $20 / 32$ & $20 / 25$ \\
\hline 18 & 87 & Male & $\mathrm{MH}$ & 12 & $20 / 100$ & $20 / 63$ \\
\hline 19 & 76 & Male & ERM & 15 & $20 / 63$ & $20 / 40$ \\
\hline 20 & 65 & Female & ERM & 10 & $20 / 50$ & $20 / 32$ \\
\hline 21 & 66 & Male & ERM & 5 & $20 / 80$ & $20 / 32$ \\
\hline 22 & 51 & Female & ERM & 5 & $20 / 80$ & $20 / 40$ \\
\hline 23 & 59 & Female & ERM & 4 & $20 / 80$ & $20 / 32$ \\
\hline 24 & 72 & Female & VTS & 19 & $20 / 100$ & $20 / 40$ \\
\hline 25 & 77 & Female & $\mathrm{MH}$ & 21 & $20 / 40$ & $20 / 32$ \\
\hline 26 & 69 & Male & ERM & 23 & $20 / 63$ & $20 / 40$ \\
\hline 27 & 61 & Female & $\mathrm{MH}$ & 19 & $20 / 100$ & $20 / 80$ \\
\hline 28 & 59 & Male & ERM & 10 & $20 / 80$ & $20 / 40$ \\
\hline 29 & 55 & Female & ERM & 5 & $20 / 100$ & $20 / 63$ \\
\hline 30 & 67 & Female & $\mathrm{MH}$ & 18 & $20 / 40$ & $20 / 32$ \\
\hline 31 & 78 & Male & $\mathrm{MH}$ & 12 & $20 / 100$ & $20 / 40$ \\
\hline 32 & 59 & Male & $\mathrm{MH}$ & 8 & $20 / 63$ & $20 / 40$ \\
\hline 33 & 51 & Female & $\mathrm{MH}$ & 9 & $20 / 40$ & $20 / 25$ \\
\hline 34 & 79 & Female & VTS & 6 & $20 / 100$ & $20 / 40$ \\
\hline
\end{tabular}

Abbreviations: ERM, epiretinal membrane; $\mathrm{MH}$, macular hole; VA, visual acuity; $\mathrm{VTS}$, vitreomacular traction syndrome.

Note: Follow-up is measured in months, age is measured in years.

in $\operatorname{sex}(\mathrm{P}=0.465$, chi-square test $)$. None of the eyes had any complication after the Nd:YAG capsulotomy.

\section{Discussion}

Posterior capsule opacification remains the most common long-term complication after cataract surgery. It can be treated by Nd:YAG laser capsulotomy, however, this may lead to other complications. It has been suggested that PCO may be significantly more extensive after combined vitrectomy and phacoemulsification than after cataract surgery alone. ${ }^{11}$ Toda and colleagues,${ }^{11}$ in a study evaluating the degree of $\mathrm{PCO}$ in patients undergoing combined cataract and vitreoretinal surgery, concluded that the PCO rate was significantly higher after combined surgery especially in patients with diabetes mellitus. After combined surgery eyes could also develop severe postoperative inflammation, which probably leads to more extensive PCO. ${ }^{12,13}$ Lens epithelial cells (LECs) proliferate in response to many factors, one of which is inflammation. It has been suggested that surgical trauma stimulates residual LECs to produce cytokines such 
Table 2 Table demonstrating the time elapsed between combined vitrectomy-phacoemulsification and posterior capsule opacification Time until PCO

\begin{tabular}{lll}
\hline Case & ERM & MH \\
\hline 1 & 10 & 12 \\
2 & 5 & 18 \\
3 & 6 & 17 \\
4 & 9 & 10 \\
5 & 11 & 19 \\
6 & 12 & 9 \\
7 & 5 & 19 \\
8 & 8 & 14 \\
9 & 11 & 16 \\
10 & 8 & 15 \\
11 & 14 & 18 \\
12 & 18 & 17 \\
13 & 6 & \\
14 & 9 & \\
15 & 11 & \\
16 & 12 & \\
17 & 19 & \\
18 & 6 & \\
\hline
\end{tabular}

Abbreviations: ERM, epiretinal membrane; $\mathrm{MH}$, macular hole; PCO, posterior capsule opacification.

Note: Time until PCO is measured in months.

as interleukin-1 (IL-1), IL-6, IL-8, basic fibroblast growth factor and transforming growth factor. These cytokines may play an important role in fibrous proliferation of LECs via an autocrine pathway, paracrine pathway, or both. ${ }^{14,15}$ The degree of postoperative inflammation appears to be related to PCO development after combined surgery even in patients without diabetes mellitus. ${ }^{11}$

Silicone IOLs have been considered to provoke PCO. ${ }^{16}$ Other factors that are considered to contribute to the formation of PCO include IOL decentration, capsulorhexis decentration, capsule tears, and insufficient zonules, but in our cases we had none of these complications.

In our study, where we chose an acrylic IOL, the capsular fibrosis in the cases dealt with combined vitrectomy and phacoemulsification was probably enhanced by accumulation of fibrin and proliferation of stimulating factors in the space between IOL and the posterior capsule. In cases treated with combined surgery the posterior capsule is "supported" by fluid or gas and not from the vitreous, as it happens in eyes undergoing cataract surgery alone; this may have a role in the induction of posterior capsular fibrosis in the early postoperative period, and this finding is in accordance with the findings of other authors. ${ }^{17,18}$ Another contributing factor to early occurrence of PCO after combined surgery, could be the inflammation which is induced by the prolonged surgery time and the combination of cataract with vitrectomy surgery.

In addition, the appearance of significant PCO seemed to have occurred earlier in the eyes that underwent combined surgery due to ERM (mean 10.0 months) compared to the patients having a $\mathrm{MH}$ preoperatively (15.33 months). Although it is difficult to draw an accurate conclusion due to the small number of patients, it seems that the use of intravitreal gas which is used in all eyes undergoing $\mathrm{MH}$ surgery-but usually not in uncomplicated vitrectomy for ERM-does not enhance the occurrence of PCO. It is not unlikely that in cases with intravitreal gas use (MH cases), the gas "supports" the posterior capsule against the IOL and narrows the space between IOL and capsule forming a barrier to cell migration. On the other hand in cases with ERM the posterior capsule is loosely "supported" by the fluid filling the vitreous cavity giving more space for cell migration between the IOL and the capsule. Additionally, the underlying condition responsible for the occurrence of the ERM such as branch retinal vein occlusion, uveitis, or previous cryotherapy or laser may have played an additional role in the earlier occurrence of PCO in eyes with ERMs.

Neodymium:YAG laser capsulotomy can cause shortand long-term IOP elevations that could possibly induce subsequent glaucoma and damage to the optic nerve. ${ }^{19}$ The underlying mechanism to this IOP rise after Nd:YAG laser capsulotomy remains unclear. Proposed mechanisms include effects to the ciliary body caused by the laser shock waves, a neurohumoral increase in the IOP, structural effects of laser energy on sodium hyaluronate, and finally mechanical blockage of the trabeculum with various debris such as fragments from the disrupted posterior capsule or vitreous. Other well established complications of Nd:YAG laser capsulotomy are retinal detachment and macular edema. ${ }^{20,21}$ Proposed mechanisms for the above complications include liquefaction of the vitreous and interruption of the anterior hyaloid face.

In our study, no major complication was observed after the YAG capsulotomy apart from transient mild IOP spikes that were easily controlled with antiglaucoma drops. The absence of complications of YAG laser in the vitrectomized eyes of our study could be attributed to the absence of vitreous, alterations of which have been considered to play an important role in the development of IOP elevation, retinal detachment, and cystoid macular edema. Interestingly, IOL decentration or dislocation did not occur in any eye after YAG laser capsulotomy and the post-Nd:YAG capsulotomy visual acuity was restored in all 34 eyes. 


\section{Conclusion}

$\mathrm{Nd}$ :YAG capsulotomy seems to be a safe and effective procedure for eyes that have previously undergone combined phacoemulsification and vitrectomy surgery.

\section{Disclosure}

The authors report no conflicts of interest in this work.

\section{References}

1. Machemer R, Buettner H, Norton WE, Parel JM. Vitrectomy: a pars plana approach. Trans Am Acad Ophthalmol Otolaryngol. 1971;75:813-820.

2. Faulborn J, Conway BP, Machemer R. Surgical complications of pars plana vitreous surgery. Ophthalmology. 1978;85:116-125.

3. McElvanney AM, Talbot EM. Posterior chamber lens implantation combined with pars plana vitrectomy. J Cataract Refract Surg. 1997;23:106-110.

4. Koenig SB, Han DP, Mieler WF, et al. Combined phacoemulsification and pars plana vitrectomy. Arch Ophthalmol. 1990;108:362-364.

5. Schaumberg DA, Dana MR, Christen WG, Glynn RJ. A systematic overview of the incidence of posterior capsule opacification. Ophthalmology. 1998;105:1213-1221.

6. Apple DJ, Solomon KD, Tetz MR, et al. Posterior capsule opacification. Surv Ophthalmol. 1992;37:73-116.

7. Keates RH, Steinert RF, Puliafito CA, Maxwell SK. Long-term follow-up of Nd:YAG laser posterior capsulotomy. J Am Intraocul Implant Soc. 1984;10:164-168.

8. Heiligenhaus A, Holtkamp A, Koch J, et al. Combined phacoemulsification and pars plana vitrectomy: Clear corneal versus scleral incisions. $J$ Cataract Refract Surg. 2003;29:1106-1112.

9. Dietlein TS, Lüke C, Jacobi PC, et al. Neodymium:YAG laser capsulotomy in vitrectomized pseudophakic eyes with persistent endotamponade. J Cataract Refract Surg. 2003;29:2385-2389.
10. Scharwey K, Pavlovic S, Jacobi KW. Combined clear corneal phacoemulsification, vitreoretinal surgery, and intraocular lens implantation. J Cataract Refract Surg. 1999;25:693-698.

11. Toda J, Kato S, Oshika T, Sugita G. Posterior capsule opacification after combined cataract surgery and vitrectomy. J Cataract Refract Surg. 2007;33:104-107.

12. Ariki G, Ogino N. [Postoperative anterior chamber inflammation after posterior chamber intraocular lens implantation concurrent with pars plana vitrectomy and lensectomy]. Nippon Ganka Gakkai Zasshi. 1992;96:1300-1305.

13. Tachi N, Kondo M, Uchida H, Ogino N. [Anterior chamber inflammation after vitrectomy in posterior vitreous membrane syndrome and phacoemulsification and intraocular lens implantation]. Nippon Ganka Gakkai Zasshi. 1995;99:329-335.

14. Nishi O, Nishi K. Intraocular lens encapsulation by shrinkage of the capsulorhexis opening. J Cataract Refract Surg. 1993;19:544-545.

15. Nishi O, Nishi K, Fujiwara T, et al. Effects of the cytokines on the proliferation of and collagen synthesis by human cataract lens epithelial cells. Br J Ophthalmol. 1996;80:63-68.

16. Hainsworth DP, Chen S-N, Cox TA, Jaffe GJ. Condensation on polymethylmethacrylate, acrylic polymer, and silicone intraocular lenses after fluid-air exchange in rabbits. Ophthalmology. 1996;103: $1410-1418$.

17. Elgohary MA, Dowler JG. Incidence and risk factors of ND:YAG capsulotomy after phacoemulsification in non-diabetic and diabetic patients. Clin Experiment Ophthalmol. 2006;34:526-534.

18. Scharwey K, Pavlovic S, Jacobi KW. [Early posterior capsule fibrosis after combined cataract and vitreoretinal surgery with intraocular air/SF6 gas tamponade]. Klin Monatsbl Augenheilkd. 1998;212:149-153.

19. Jahn CE, Emke M. Long-term evaluation of intraocular pressure after neodymium-YAG laser capsulotomy. Ophthalmologica. 1996;210:85-89.

20. Powell SK, Olson RJ. Incidence of retinal detachment after cataract surgery and neodymium:YAG laser capsulotomy. $J$ Cataract Refract Surg. 1995;21:132-135.

21. Jacobi FK, Hessemer V. Pseudophakic retinal detachment in high axial myopia. J Cataract Refract Surg. 1997;23:1095-1102. 
